\section{Weibel-Palade bodies in Kaposi's sarcoma} cells

Russell Jones et al recently reported immunohistochemical findings which favour the hypothesis that Kaposi's sarcoma cells are derived from lymphatic endothelium. ${ }^{1}$ They stated that "ultrastructural observations of AIDS (acquired immune deficiency syndrome) and non-AIDS related Kaposi's sarcoma have failed to identify Weibel-Palade bodies commonly regarded as a marker for vascular endothelium." Some authors, however, have found such bodies in cells from both classical ${ }^{23}$ and AIDS associated Kaposi's sarcoma. ${ }^{4}$

By means of electron microscopy we investigated biopsy material from eight patients with endemic Kaposi's sarcoma and five patients with AIDS associated African Kaposi's sarcoma. The tumour specimens had been excised from patients in Uganda. Blood serum samples from the five patients with AIDS associated Kaposi's sarcoma were positive for antibodies to the human immunodeficiency virus. We noted occasional Weibel-Palade bodies in cells from both forms of Kaposi's sarcoma after extensive search (figs 1 and 2). The bodies were found only in endothelial cells which formed capillaries (figs 1 and 2). They were not present in spindle shaped tumour cells, which predominantly resembled fibroblasts and myofibroblasts.

The ultrastructure of the angiomatous cells containing Weibel-Palade bodies indicated that they did not represent typical endothelial cells of tumour supplying blood capillaries; instead they were atypical neoplastic cells. They were often seen bulging into the capillary lumen and were characterised by a relatively prominent rough surfaced endoplasmic reticulum, numerous intracytoplasmic microfilaments, and occasional tubuloreticular structures (figs 1 and 2).

We think that the cell of origin of Kaposi's sarcoma with or without AIDS is a primitive mesenchymal cell of the perivascular space. This cell may differentiate into an endothelial cell or a pericyte of a blood $\stackrel{0}{F}$ capillary as well as into a spindle shaped $\underline{\underline{0}}$ tumour cell.

KH MARQUART $\overline{\bar{\sigma}}$ Institute of Pathology, $\overline{\mathrm{C}}$ Gesellschaft für Strahlen- und 흐 Umweltforschung $\mathrm{mbH}$ München, $\overline{\overline{\mathrm{D}}}$ D-8042 Neuherberg, Federal Republic of Germany

References

1 Russell Jones R, Spaull J, Spry C, Wilson Jones $\vec{\circ}$ E. Histogenesis of Kaposi's sarcoma in $\overrightarrow{\vec{H}}$ patients with and without acquired immune deficiency syndrome (AIDS). $J$ Clin Pathol 1986;39:742-9.

2 Gokel JM, Kürzl R, Hübner G. Fine structure

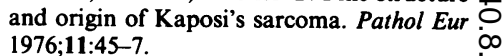

3 Daimont Waldo E, Vuletin JC, Kaye GI. The ultrastructure of vascular tumors: additional $\omega$ observations and a review of the literature. $\frac{1}{\sigma}$ Pathol Ann 1977;12(2):279-308.

4 Leu HJ, Schneider J, Hardmeier T, et al. Kaposi's sarcoma and malignant lymphoma in AIDS. Virchows Arch (Pathol Anat) 1984;403:205-12.

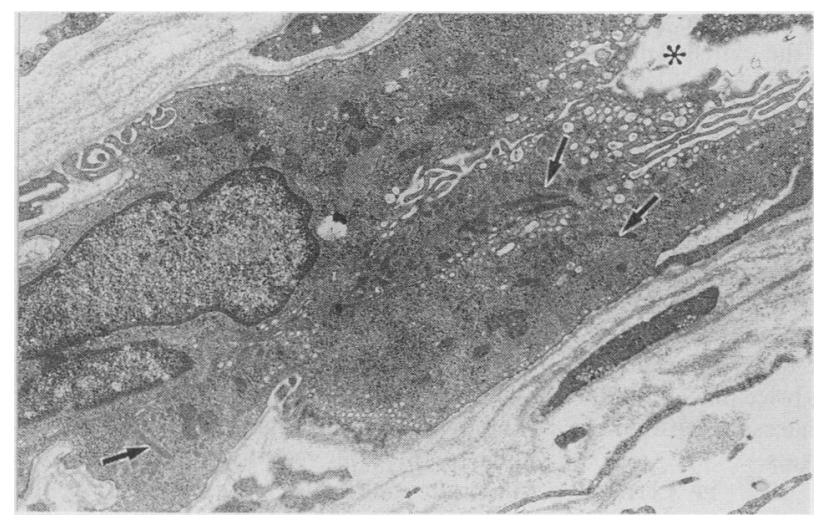

Fig 1 Part of a blood capillary from an endemic African Kaposi's sarcoma. Atypical thick endothelium bulges into capillary lumen (asterisk) and is surrounded by cell processes of pericytes and a reduplicated basal lamina. Rod shaped Weibel-Palade bodies are present in endothelial cytoplasm (arrows).

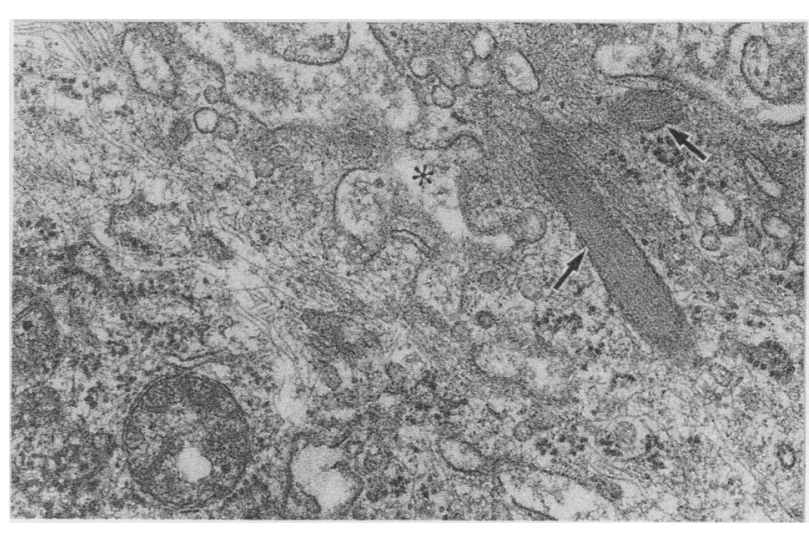

Fig 2 Portion of a capillary endothelial cell from an AIDS associated African Kaposi's sarcoma. Two Weibel-Palade bodies (arrows) are located in cytoplasm near to capillary lumen (asterisk). Intracytoplasmic tubuloreticular structure can be seen in lower left corner of the picture.

\section{Book reviews}

The Geography of Non Infective Disease. MSR Hutt, DP Burkitt. (Pp 184; hard back $£ 22.50$; soft cover $£ 12.50$.) Oxford University Press. 1986. ISBN 0-19-261-5971 (hardback); ISBN 0-19-261-4517 (soft cover).

Except in the most motivated of people careers develop in a haphazard opportunistic way; frequently fashioned by those one works for or meets in the clinical hurly burly. In the mid sixties my own views of what I wanted to do were much influenced by Michael Hutt and Denis Burkitt, who from the high ground of Makerere, came to the support of a particular piece of Glasgow flotsam washed up on the beaches of Dar es Salaam. In a variety of ways their enthusiasm for geographical pathology showed me that the value of pathology was much more than simple diagnosis or even painstaking complicated morphological classifications. When coupled with epidemiology-however coarse the local constraints-geographical pathology was an exciting investigative tool $\tilde{\sigma}$ often neglected in Britain but very successful N in the tropics in defining those areas worthy of detailed investigation.

In Geography of Non Infectious Disease the authors have brought together the main facts of the associations of geographical environment and non-infective disease. They have produced a synoptic view written in a style which raises enthusiasms (and also some regrets that the British effort in tropical medicine and pathology is now so meagre and apparently spent). This is a book partic- 
ularly for young men and women who need to be reminded that modern advances are all very well, but simple observations properly recorded and interpreted with insight are still the basis of major advances. I recommend this book unreservedly to all those training in pathology in whatever speciality and hope it may stimulate a few adventurous souls to try, at least for a short period, to work away from the NHS norms of Harrow and Hackney. I recommend it also to those pathologists aged 55 who still retain some vision. It will act as a powerful stimulant to those seeking early retirement and to work overseas in the twilight of their careers, perhaps rekindling the enthusiasms of youth. This is a splendid book. Buy it.

G SLAVIN

Methods of Enzymatic Analysis. 3rd ed. Vol XI. Antigens and Antibodies 2. Ed-in-Chief HU Bergmeyer. Eds J Bergmeyer, M Grassi. (Pp 508; no price given.) VCH. 1986. ISBN 3-527-26052-8.

The third edition of this volume provides a valuable update and a refreshing insight into methods of enzymatic analysis as applied to antigen and antibodies. The main thrust of the book is centred on the ELISA technique and the various ways it can be manipulated for antigen and antibody detection. Clearly some of the techniques are still in the developmental stage so that their role as diagnostic tests is unclear but the book does provide detailed protocols so that one can develop these tests further. The increase in interest in the serodiagnosis of infectious diseases makes this a most interesting read.

RUTH MATTHEWS

Progress in Neuropathology. Vol 6. Ed HM Zimmerman. (Pp 304; \$98.50.) Raven Press. 1986.

Dr Zimmerman has again been responsible for the publication of an excellent and informative book. I agree with his statement in the Preface that some of the contributions are aimed not so much at morphology but to provide insights into the mechanisms by which morphological changes occur, hence the wide range of topics encompassed by the 13 chapters. It may seem invidious to commend particular chapters since neuroscientists in different fields will be attracted to particular topics. As a neuropathologist, however, I found the chapters on cytoskeletal abnormalities, tumour invasion and metastasis, experimentally induced brain tumours, neuron specific enolase and neuroendocrine models of brain transplantation particularly interesting and instructive. Others might find their greatest interest in the inflammatory cell infiltrates in experimental allergic encephalomyelitis, or in the congenital myopathies. And it was also interesting to learn that the glucocorticoids may be modulators of neuropathological insults in the hippocampus. As with the previous volumes, this one must be available in any department professing an interest in the neurosciences.

J HUME ADAMS

Pathogenesis of Liver Diseases. International Academy of Pathology Monograph. Eds E Farber, MJ Phillips, N Kaufman. (Pp 384; 81.) Williams \& Wilkins. 1986. ISBN 0-683-03038-8.

This volume is based on the annual long course that was held by the United States/Canadian Division of the IAP in 1986 and it is a worthy successor to its predecessors. The chosen theme is reflected over a wide field: viral and chemical carcinogenesis, immunopathology, ultrastructure, chemistry of the cell, role of the cytoskeleton in health and disease, and much else besides. The longest chapter by Ishak surveys the recent literature on diagnostic liver pathology with 921 references, a truly encyclopaedic cover of the subject. It is indeed a condensed textbook of liver pathology in itself. The editors must be congratulated on the speedy production of this compendium and the publishers on its high physical quality. It is a must for all those interested in liver disease, but its high price places it in the category of library purchases rather than the range of individual pockets.

PP ANTHONY

Atlas of Tumors of the Facial Skeleton. Odontogenic and Nonodontogenic Tumors. J Prein, W Remagen, B Spiessel, E Uehlinger. (Pp 162; DM 368.) Springer. 1986. ISBN 3-540-16167-8.

This book is based on 1256 cases contributed by clinics and laboratories in 53 cities to a Registry established in 1971 by Dösak (German Austrian Swiss Association for the Study of Tumors of the Face and Jaws). Seventeen chapters deal with tumours, tumour like lesions and cysts arising from odontogenic tissues, and a further 17 deal with tumours and tumour like lesions of bone. Each chapter describes a single type of lesion, and consists of a short text followed by clinical radiographs and photomicrographs; all of the latter are in colour. The text gives a summary of each lesion under the subheadings "synonym䒕, "history", "epidemiology", "clinical fe्थ tures", "radiographic features", "m将phology", "differential diagnosis" (bofth radiographic and histological) a®d "remarks". The translation from the Ge्rman is excellent, and mostly of these summaries are helpful, but those on "symonyms" are full of traps for the unwary, ahd "differential diagnosis" sometimes omôts common and difficult problems. The radisgraphs are mostly good, but the photomicrographs are rather variable, and the illustrations do not always bring opt important diagnostic features. This attrgtive atlas illustrates well the value of bringing together the clinical and pathologieal evidence; it is a useful supplement to moffe formal texts, but is too brief to be useed alone.

IRH KRAMER

Recent Advances in Anaerobic Bacteriology. New Perspectives in Clinical Microbiology. SP Borriello, JM Hardie. (Pp 337; £65. Martinus Nijhoff. 1986. ISBN 0-89838-847-3.

Many of the chapters are expert contributions that review the state of the art gs it was in 1985; these include Eley and Gre wood on newer antibiotics, Hamilton on sfphate reducing bacteria, and Taylor amd Phillips on the taxonomy of anaerobic cocol. Some of the papers, however, are franky "pot boilers".

One departure from conventional tre $\overline{\mathrm{q}} \mathrm{t}-$ ment of scientific publications is the inctasion of group photographs (of uniformy poor quality) of symposium contributefs. These are unhelpful, and, mindful of the published price of $£ 65.75$ (about 14 woछls per penny), they should have been omitted. Editorial problems, such as duplication $\delta$ f one full page of the List of Contributors, and misspelling of the name of Professor Eossmon, are infrequent.

The book is handsomely bound, but high price will ensure a restricted marke: AT WInghys

ก

Neoplasia in Infancy and Childhood. Persperctives in Pediatric Pathology. Vol. 9. Ed GiS Rosenberg, J Bernstein, WA Newton. ${ }_{p}$ 248; £100.) S Karger. 1986. ISPN 3-8055-437-5.

This volume of six review articles contarips four contributions in specific areas 9 f pathology-histiocytosis $\mathrm{X}$, lymphohis cytosis, leukaemia and osteosarcoma. Thorre are two reviews on general topics; the rolefof 